\title{
BREVES CONSIDERAÇÕES ACERCA DO CONTROLE JURISDICIONAL DE POLÍTICAS PÚBLICAS EM FACE DO DIREITO FUNDAMENTAL AO MEIO AMBIENTE ECOLOGICAMENTE EQUILIBRADO
}

Short comments on the jurisdictional control of public policies in the face of the fundamental right to a balanced environment

${ }^{1}$ Universidade Tecnológica Federal do Paraná. Curitiba/PR, Brasil.

${ }^{2}$ Pontifícia Universidade Católica do Paraná. Curitiba/PR, Brasil.

Correspondência: Ana Paula Myszczuk. E-mail: anap@utfpr.edu.br.

Recebido em: 08/01/2016. Revisado em: 09/03/2016. Aprovado em: 11/03/2016. 


\section{RESUMO}

O presente artigo tem por objetivo realizar um breve comento sobre o Recurso Especial n. 1.367.549 - MG (2011/0132513-5), julgado pelo Superior Tribunal de Justiça, que analisa a possibilidade da utilização do controle judicial de políticas públicas em face de falta de prestações positivas por parte da Administração Pública na área ambiental. Dessa forma, o artigo apresenta um resumo comentado da decisão e traça algumas considerações sobre as políticas públicas municipais. Além disso, discute a possibilidade do uso do controle judicial de políticas públicas em face de direitos fundamentais e, por fim, o papel do Ministério Público no controle social de políticas públicas.

\section{Palavras-Chave}

Controle Jurisdicional; Direitos Fundamentais; Meio Ambiente; Ministério Público; Políticas Públicas.

\section{ABSTRACT}

This article aims to make a brief commentary about the appeal 1367549 MG 2011/0132513-5, judged by the Brazilian Superior Court of Justice, which examines the possibility of using the judicial review of public policies in the face of a lack of positive benefits in the public administration in the environmental field. Thus, the article presents a summary of the judgment and some considerations on municipal public policies. In addition, it conducts a discussion about the possibility of using the judicial review of public policies in the face of fundamental rights and, finally, analyzes the role of the Brazilian Federal Prosecutor.

\section{Keywords}

Brazilian Federal Prosecutor; Environment; Fundamental Rights; Jurisdictional Control; Public Policies. 


\section{EMENTA}

PROCESSO CIVIL. ADMINISTRATIVO. AÇÃO CIVIL PÚBLICA. OBRIGAÇÃO DE FAZER. DANO AMBIENTAL. IMPLEMENTAÇÃO DE OBRA PÚBLICA. USINA DE RECICLAGEM DE RESÍDUOS SÓLIDOS. INGERÊNCIA DO PODER JUDICIÁRIO. VIOLAÇÃO DO PRINCÍPIO DA SEPARAÇÃO DOS PODERES. INEXISTÊNCIA. VIOLAÇÃO AO ART. 333, I, DO CPC CARACTERIZADA. 1. Cinge-se a controvérsia dos autos à possibilidade do Ministério Público, em obrigação de fazer, por meio de ação civil pública, compelir o administrador a implementar obra pública, qual seja, usina de reciclagem de entulhos provenientes da construção civil, que estivesse causando danos ao meio ambiente. 2. Irretocável, a posição do Supremo Tribunal Federal e desta Corte, no sentido de que "O Poder Judiciário, em situações excepcionais, pode determinar que a Administração Pública adote medidas assecuratórias de direitos constitucionalmente reconhecidos como essenciais, sem que isso configure violação do princípio da separação de poderes” (AI 708667 AgR, Relator (a): Min. DIAS TOFFOLI, Primeira Turma, julgado em 2802/2012). 3. Reconheço que em algumas situações é impossível estabelecer, num plano abstrato, qual a ordem de prioridades que a atividade administrativa deve tomar. Nestes casos, a identificação pela preferência de atuação estatal apenas poderia ser identificada na análise do caso. Todavia, ainda que abstratamente, não se pode deixar de reconhecer que alguns direitos, tais como a educação, a saúde e o meio ambiente equilibrado fazem parte de um núcleo de obrigações que o Estado deve considerar como prioritárias. 4. Deve ser afastada a aplicação da Súmula 7/STJ e reconhecida a ofensa ao artigo 333, I, do CPC. Isto porque a Corte de origem faz referência a vários elementos probatórios que induzem - em tese - a existência de dano ambiental, considerando, também, que durante a tramitação do processo ocorreu significativa melhora no sistema de destinação dos resíduos sólidos, em especial, com aprovação da lei municipal regulamentando o tema. No entanto, apesar disso, o pleito do Ministério Público Estadual foi indeferido em razão da ausência de provas. 5. Os autos devem ser devolvidos ao primeiro grau para que o juiz proceda à instrução levando em conta o art. 462 do CPC e a Lei n. 12.305/2010 (Lei da Política Nacional de Resíduos Sólidos), sobretudo à luz do se art. 54. Recurso especial parcialmente provido. (REsp 1367549/MG Recurso Especial 2011/0132513-5, Relator: Humberto Martins, Segunda Turma, Julgamento em: 02/09/2014.

\section{Introdução}

A possibilidade da utilização de controle social e jurisdicional de políticas públicas ainda é bastante discutida, tendo em vista o princípio da separação dos Poderes. Porém, na atualidade do Estado brasileiro e com o crescente movimento do ativismo jurídico, o Poder Judiciário e o Ministério Público vêm tomando a posição de que, entre suas funções, está atuar para garantir que a Administração Pública cumpra com as obrigações positivas em relação ao administrado, garantindo a positivação do mínimo existencial. 
Nesse contexto, o presente artigo comenta o Recurso Especial n. 1.367.549-MG (2011/0132513-5), que trata da possibilidade do controle jurisdicional de políticas públicas diante da falta de prestação positiva por parte da Administração Pública, em face do direito fundamental ao meio ambiente ecologicamente equilibrado.

\section{0 caminho da decisão judicial em comento}

Trata-se do Recurso Especial n. 1.367.549 - MG (2011/0132513-5), decorrente de ação civil pública proposta pelo Ministério Público de Minas Gerais em face do Município de Uberlândia, tendo em vista os danos ao meio ambiente causados pelos entulhos da construção civil e com o objetivo de que o Município fosse compelido a executar obra pública concernente a uma usina de reciclagem de resíduos sólidos.

$\mathrm{Na}$ ação se pode constatar que, nos idos de 1998, naquele Município, existiam várias centrais de entulho que estariam causando grave degradação ao meio ambiente. O Parecer Técnico de maio de 2001 dá conta de que não havia controle do material depositado. Em 2003, em audiência junto à Promotoria Estadual, o Secretário Municipal de Meio Ambiente e Desenvolvimento Sustentável relatou existência de uma política atual e efetiva, comprometida com o meio ambiente, e que estaria em tramitação um Projeto de Lei - aprovado em 26 de junho de 2006, Lei Municipal n. 9.244 - que instituía o sistema municipal para gestão sustentável de resíduos da construção civil. Em 2007, foi verificado que ainda havia muito lixo nas centrais. A partir dessa situação, o Ministério Público propôs a referida ação civil pública.

A primeira instância e o Tribunal de Justiça do Estado de Minas Gerais entenderam que o Município de Uberlândia possuía legislação que atendia ao interesse da população local, no sentido de implementar uma política pública para gestão dos entulhos da construção civil. Julgaram improcedente o pedido, tendo em vista que a escolha da realização de obra pública específica seria ato discricionário do Poder Executivo a ser realizado de acordo com sua conveniência.

A questão chegou ao Superior Tribunal de Justiça (STJ), que entendeu que o ponto controvertido era a possibilidade do controle jurisdicional de políticas públicas. O relator, ministro Humberto Martins, destaca que o Poder Judiciário sofreu alterações em sua estrutura funcional, tendo sua margem de atuação ampliada, de modo a possibilitar a efetividade dos direitos sociais. Reforça que o princípio da separação dos Poderes, nos dias atuais, deve ser compreendido com temperamentos e ajustes à luz de diferentes realidades constitucionais. Fundamenta seu entendimento na decisão da Corte Suprema, proferida nos autos da ADPF-45, em que se entende que

poderá atribuir-se ao Poder Judiciário, se e quando os órgãos estatais competentes, por descumprirem os encargos políticos-jurídicos que sobre eles incidem, vierem a comprometer, com tal 
comportamento, a eficácia e integridade de direitos individuais e/ou coletivos impregnados de estatura constitucional, ainda que derivados de cláusulas revestidas de conteúdo programático

Crê que os direitos sociais não podem ficar condicionados à boa vontade do administrador, sendo de fundamental importância que o Judiciário atue como órgão controlador da atividade administrativa quando a Administração Pública, de maneira clara e indubitável, viola direitos fundamentais. Nesse caso, a interferência do Poder Judiciário seria perfeitamente legítima e serviria como instrumento para restabelecer a integridade da ordem jurídica violada. A partir desse fundamento, entende que o Poder Judiciário pode determinar que a Administração Pública adote medidas assecuratórias de direitos constitucionalmente reconhecidos como essenciais. O Judiciário não mais se limita a examinar os aspectos extrínsecos da administração, mas abrange as razões de conveniência e oportunidade, uma vez que estas devem observar critérios de moralidade e razoabilidade. Seu voto foi acompanhado de forma unânime.

\section{Políticas públicas, controle social e direitos fundamentais}

De maneira geral, uma política pública pode ser definida como o que o governo escolhe fazer ou não fazer ${ }^{1}$. Portanto, consiste em ações do governo destinadas a resolver uma(s) necessidade(s) pública(s). Nesse sentido, podem ser: sociais (saúde, assistência, habitação, educação, emprego, renda ou previdência), macroeconômicas (fiscal, monetária, cambial, industrial) ou outras (científica e tecnológica, cultural, agrícola etc. $)^{2}$. Ao mesmo tempo, visa a colocar o governo em ação, analisar essa ação e, quando necessário, propor mudanças no rumo ou curso das mesmas. Em outras palavras, é o momento em que os governos democráticos transformam seus propósitos e plataformas eleitorais em programas e obras que possam produzir resultados ou mudanças no mundo real $l^{3}$.

O voto do relator, ministro Humberto Martins, destaca o papel do Estado na gestão pública lembrando que, a partir da consolidação constitucional dos direitos sociais, a função estatal foi profundamente modificada, deixando de ser eminentemente legisladora em prol das liberdades públicas para se tornar mais ativa, com a missão de concretizar políticas de transformação da realidade social.

Contudo, o orçamento público, especialmente o municipal, não pode abarcar todas as políticas públicas demandadas pela sociedade e/ou necessárias

\footnotetext{
${ }^{1}$ DYE, Thomas D. Understanding public policy. Englewood Cliffs, N.J.: Prentice-Hall, 1984.

${ }^{2}$ GELINSKI, Carmen Rosario Ortiz G.; SIEBEL, Erni José. Formulação de políticas públicas: questões metodológicas relevantes. Revista de Ciências Humanas, Florianópolis, EDUFSC, v. 42, n. 1/2, abr./out. 2008.

${ }^{3}$ SOUZA, Celina. Políticas públicas: uma revisão da literatura. Sociologias, Porto Alegre, ano 8, n. 16, p. 20-45, jul./dez. 2006. Disponivel em: <http://www.scielo.br/pdf/soc/n16/a03n16.pdf>. http://dx.doi. org/10.1590/S1517-45222006000200003.
} 
à continuidade do Estado, tendo em vista a escassez de recursos. Assim, na elaboração do orçamento público, definem-se aquelas que serão contempladas e, desse grupo, quais as prioritárias e quais contingenciadas e/ou canceladas. Nesse contexto, o gestor municipal tem ampla competência para definir suas políticas e aplicar recursos orçamentários. Somente as áreas de educação, saúde e previdência social, de acordo com o que determina a Constituição Federal de 1988, têm a obrigatoriedade de dispêndio mínimo em relação à arrecadação ao erário. Quer dizer, essas são as áreas prioritárias; todas as outras, incluindo a do meio ambiente, são secundárias.

Logo, em existindo uma limitação no orçamento, obrigatoriedade de atendimento de determinados direitos sociais - dentre outras vinculações, como o exercício da dívida pública, o pagamento da folha de pessoal e o dispêndio com a manutenção do aparelho estatal -, a discricionariedade de gestor público recai com maior ênfase sobre as políticas púbicas secundárias. A política pública chamada "secundária" ou "discricionária" é aquela cuja escolha esteja a cargo do agente público, como parte integrante de um processo que abrange o plano de governo, o orçamento público e sua implementação ${ }^{4}$.

Por estar inserido no contexto das políticas púbicas de prioridade secundária, talvez o maior problema da proteção ambiental resida exatamente na omissão dos órgãos ambientais no desenvolvimento de atividades eficientes de fiscalização, realização de obras ou prestação de serviços públicos, contribuindo para a degradação e poluição do meio ambiente ${ }^{5}$.

Há que se considerar, no entanto, que em algumas áreas secundárias que envolvem direitos fundamentais, o Estado tem um dever - representado numa obrigação de fazer - de prestar serviços de natureza continuada e essenciais à vida em sociedade. Essa obrigação representa uma conduta positiva do Estado, que pode ser traduzida em prestações de natureza material ou normativa ${ }^{6}$ e representa um limite à discricionariedade do gestor público. No abrigo dessa proteção, incluem-se: segurança pública e defesa civil; coleta e tratamento de lixo; coleta e tratamento de resíduos sólidos e efluentes; manutenção de vias e mobiliário público; postagem e telefonia; eletrificação; entre outros ${ }^{7}$.

\footnotetext{
${ }^{4}$ DORNELLAS, Eduardo Dias. Execução orçamentária como instrumento para a priorização de políticas públicas municipais secundárias: um estudo no município de Adrianópolis. 2015. Dissertação (Mestrado) - Programa de Pós-Graduação em Planejamento e Governança Pública, Universidade Tecnológica Federal do Paraná, 2015.

${ }^{5}$ MACHADO, Lucélia Simioni. Ponderação de bens e otimização do direito ao meio ambiente ecologicamente equilibrado na colisão de direitos fundamentais: uma abordagem a partir da teoria dos direitos fundamentais de Alexy. 2014. Dissertação (Mestrado) - Programa de Pós-Graduação em Direito da Universidade de Caxias do Sul, 2014.

${ }^{6}$ MELLO, Maria Elisa Santos de Andrade. Controle judicial das políticas públicas. 2013. Monografia (Especialização) - Escola da Magistratura do Rio de Janeiro. Rio de Janeiro, 2013.

${ }^{7}$ MACHADO, Lucélia Simioni. op. cit.
} 
Consequentemente, a discricionariedade do gestor público na implementação de políticas públicas na área ambiental, mormente no que tange ao manejo de resíduos sólidos, está limitada pelo cumprimento, a contento, dessa obrigação de fazer. Frise-se que há várias maneiras de se tratarem os resíduos sólidos, tais como incineração, compostagem, autoclavagem, pirólise, micro-ondas etc. A separação dos resíduos recicláveis nas fontes geradoras também é considerada uma forma de tratamento, aplicável principalmente aos resíduos domiciliares ${ }^{8}$.

A partir dessas questões, conjectura-se: se o titular do direito fundamental tem um direito em face do Estado - direito representado por uma ação positiva deste -, então, por outro lado, o Estado tem o dever de realizar a referida ação para o titular9. Portanto, sempre que entre um titular de direito fundamental e o Estado houver esse tipo de obrigação, o titular do direito fundamental tem a competência de exigir judicialmente esse direito. Assim, se a municipalidade não cumpre ou cumpre apenas parcialmente esse dever de prestação continuada, pode ensejar a interferência externa para a garantia de direitos fundamentais.

Uma vez constatada inércia ilícita da Administração Pública em dar efetividade ao direito ao meio ambiente ecologicamente equilibrado, o ente estatal estará sujeito aos sistemas de controle previstos na ordem jurídica brasileira: o controle social exercido pelo Ministério Público e pelo Poder Judiciário ${ }^{10}$.

\section{0 meio ambiente ecologicamente equilibrado enquanto direito fundamental e controle jurisdicional de políticas públicas}

Os direitos fundamentais são condição imprescindível para a existência do Estado democrático de direito, tornando-se um critério de legitimação desse poder constituído e da ordem constitucional. Esses direitos, na Constituição Federal de 1988, são instrumentos de defesa da liberdade individual e elementos integrantes do sistema axiológico, e atuam como fundamento material de todo o ordenamento jurídico.

A Constituição de 1988, em seu artigo $225^{11}$, consagra o direito fundamental ao meio ambiente ecologicamente equilibrado, que é categorizado enquanto

\footnotetext{
${ }^{8}$ IKUTA, Flávia Akemi. Resíduos sólidos urbanos no Pontal do Paranapanema/SP: inovação e desafios na coleta seletiva e organização de catadores. 2010. Tese (Doutorado) - Programa de Pós-Graduação em Geografia da Universidade Estadual Paulista. Presidente Prudente, 2010. p. 32.

${ }^{9}$ DORNELLAS, Eduardo Dias. op. cit.

${ }^{10}$ FERREIRA, Ximena Cardozo. A atuação do Ministério Público na implementação de políticas públicas da área ambiental. Revista de Direito Ambiental, São Paulo, 2012. Disponível em: <http://www.mprs.mp.br/ ambiente/doutrina/id377.htm>. Acesso em: 05 out. 2016.

11“Art. 225. Todos têm direito ao meio ambiente ecologicamente equilibrado, bem de uso comum do povo e essencial à sadia qualidade de vida, impondo-se ao Poder Público e à coletividade o dever de defendê-lo e preservá- lo para as presentes e futuras gerações." BRASIL. Constituição da República Federativa do Brasil de 1988. Disponível em: <http://www.planalto.gov.br/ccivil_03/constituicao/constituicaocompilado. $\mathrm{htm}>$. Acesso em: 09 set. 2016.
} 
bem de uso comum do povo, essencial à sadia qualidade de vida das presentes e futuras gerações e cuja proteção é de responsabilidade compartilhada. Quer dizer, Estado e sociedade têm o dever de protegê-lo e oferecer as condições necessárias para promovê-lo.

Essa determinação acarreta o dever do Poder Público de tomar tanto condutas positivas como abstenções de atividades que possam causar danos ao meio ambiente. Ora, a inação por parte da municipalidade, que não vê oportunidade ou conveniência em realização de obra que vá pôr fim à ocorrência de determinados danos ambientais, já se consagra numa violação dos direitos fundamentais da população e enseja a possibilidade de atuação do Ministério Público e o controle das políticas públicas por parte do Poder Judiciário. Destaca-se, especialmente, sobre o tema da ação civil pública em comento:

Os resíduos sólidos são considerados um dos grandes problemas das sociedades contemporâneas, manifestando-se com mais força nas áreas urbanas, onde agravam problemas ambientais já existentes e levam ao aparecimento de outros, quase sempre relacionados às formas ineficientes de gestão. Desta forma, este tema se constitui como um grande desafio ao planejamento e gestão urbana, uma vez que a maneira como ocorre a gestão e o gerenciamento dos resíduos sólidos interfere de forma direta ou indireta no cotidiano de todos os cidadãos, com implicações sobre a qualidade ambiental e de vida nas cidades (onde se concentra a maior parte da população no Brasil) ${ }^{12}$.

Portanto, a proteção do meio ambiente de agentes que causem sua degradação, como é o caso dos resíduos sólidos, é uma forma de se dar efetividade aos direitos fundamentais. Por óbvio que, a partir desse entendimento constitucional, as políticas públicas devem garantir, de forma articulada com a sociedade, o desenvolvimento sustentável - quer dizer, que englobe o desenvolvimento socioeconômico e a preservação do meio ambiente.

É de se ressaltar que, no próprio acórdão, o relator cita outra decisão do próprio STJ, na qual entende que

a questão do lixo é prioritária, porque estão em jogo a saúde pública e o meio ambiente... A coleta do lixo e a limpeza dos logradouros públicos são classificados como serviços públicos essenciais e necessários para a sobrevivência do grupo social e do próprio Estado, porque visam a atender as necessidades inadiáveis da comunidade (REsp 575998/MG, Rel. Min. Luiz Fux, Primeira Turma, julgado em 7/10/2004, DJ 16/11/2004.).

\footnotetext{
${ }^{12}$ IKUTA, Flávia Akemi. op. cit., p. 32.
} 
A ausência de uma política pública adequada em termos de coleta, tratamento, reciclagem e destinação final do lixo e a produção de grandes quantidades de resíduos acarretam a poluição do solo, dos lençóis freáticos, dos mananciais e do ar. Com isso, fica claro que a adoção de medidas que visem à melhoria da qualidade de vida da população se confunde com medidas de proteção ao meio ambiente. Assim, a omissão estatal é maléfica para toda a sociedade, e a inexistência de políticas públicas prejudica toda a sociedade, à medida que se configura extremamente danosa ao meio ambiente ${ }^{13}$.

Vale dizer que não só o direito ao meio ambiente ecologicamente equilibrado é um direito fundamental, mas a questão do manejo do lixo, na qual a destinação de resíduos sólidos está inserida, é de natureza essencial à possibilidade da existência da sadia qualidade de vida da população. Assim, sua efetivação não pode ficar a cargo exclusivo da decisão do Executivo, dentro de sua conveniência e oportunidade, mas é caso clássico de possibilidade de intervenção do Ministério Público e do Poder Judiciário por meio do controle jurisdicional de políticas públicas, tendo em vista se tratar de direito fundamental.

\section{Controle jurisdicional de políticas públicas, o papel do Ministério Público e a efetivação de direitos fundamentais}

\section{Controle jurisdicional de políticas públicas}

O controle das políticas públicas pelo Poder Judiciário, na concepção clássica de separação de funções do Estado gestada no Estado liberal, é impossível. Nesse modelo, cabia à Administração Pública o dever de abstenção diante das liberdades negativas dos indivíduos e era atribuída aos juízes a mera subsunção do fato à norma jurídica, proibindo-se qualquer atividade criadora do direito ${ }^{14}$.

Tal visão clássica não mais prevalece na atualidade, porquanto o surgimento do Welfare State (Estado de bem-estar social) trouxe obrigações positivas para a Administração Pública e a tutela do Poder Judiciário deixou de ser limitada à defesa de direitos ou liberdades negativas dos administrados perante o Poder Público - passando ao campo hermenêutico, para a interpretação e, em alguns casos, criação de normas. Especificamente no caso em comento, o relator explica:

A ilicitude gerada pelo não cumprimento injustificado do dever da Administração Pública em implementar políticas de governo

\footnotetext{
${ }^{13}$ ANDRADE, Pierre André da Rocha. Controle jurisdicional de políticas públicas: Estado Democrático de Direito e hermenêutica. 2008. Dissertação (Mestrado) - Programa de Pós-Graduação em Direito da Universidade Estácio de Sá. Rio de Janeiro: 2008.

${ }^{14}$ SILVA, Priscilla Lima de Carvalho. A judicialização da política e o controle judicial de políticas públicas: uma abordagem do tema na perspectiva da racionalidade das decisões judiciais. In: SEMINÁRIO INTERNACIONAL DE DEMANDAS SOCIAIS E POLITICAS PÚBLICAS NA SOCIEDADE CONTEMPORÂNEA, 11., 2014.
} 
acarreta a desarmonia da ordem jurídica, o que faz merecer correção judicial, sob pena de transformar em letra morta os direitos sociais... Dessa forma, não podem os direitos sociais ficar condicionados à boa vontade do Administrador, sendo de fundamental importância que o Judiciário atue como órgão controlador da atividade administrativa... Seria distorção pensar que o princípio da separação dos Poderes, originalmente concebido com o escopo de garantia dos direitos fundamentais, pudesse ser utilizado justamente como óbice à realização dos direitos sociais, igualmente fundamentais ${ }^{15}$.

O reconhecimento de que certos direitos difusos e coletivos estão relacionados a políticas públicas e que ficam na dependência da ação governamental para ser efetivados gera a possibilidade de que esses conflitos, antes restritos à esfera política, ganhem foro judicial e recebam solução mediante a aplicação técnica do direito ${ }^{16}$.

Isso reflete o que hoje se passou a chamar de ativismo judicial, que é uma forma específica e proativa de hermenêutica constitucional, sendo uma atitude assumida pelo Poder Judiciário para a garantia da eficácia das obrigações positivas da Administração Pública. Desse modo, o controle das políticas públicas pelo Poder Judiciário se apresenta como uma positivação do direito fundamental de acesso à justiça e da obtenção da tutela jurisdicional sobre quaisquer matérias ${ }^{17}$. A esse novo encaminhamento de conflitos de interesse - da política para a Justiça - é que se pode denominar de judicialização da política.

Esse controle, entretanto, não é irrestrito e deve ser utilizado apenas em situações pontuais, sob pena de se infringir os limites da separação dos Poderes. Representa um instrumento essencial para o gerenciamento e a análise de resultados da Administração Pública, sendo uma garantia para a população de otimização dos recursos públicos, usados sem desperdício ou desvios ${ }^{18}$.

Mas, quando a falta da prestação de obrigação positiva por parte do Poder Público poderia dar causa ao controle social de políticas públicas? O exercício do poder de controle imanente ao sistema deve ser perseguido pelo Ministério Público e realizado pelo Judiciário dentro dos exatos limites de suas funções, não podendo sobrepor-se a decisões, também razoáveis e revestidas de legalidade, da Administração Pública ${ }^{19}$. Assim sendo, o controle social será possível sempre que a Admi-

\footnotetext{
${ }^{15}$ Recurso Especial 1367549 MG 2011/0132513-5.

${ }^{16}$ ARANTES, Rogério Bastos. Direito e política: o Ministério Público e a defesa dos direitos coletivos. Revista Brasileira de Ciências Sociais, v. 14, n. 39, p. 82-103, fev. 1999. Disponível em: <http://www.scielo.br/ pdf/rbcsoc/v14n39/1723>.

${ }^{17}$ Id. Ibid.

${ }^{18}$ BLANSKI, Beatriz Schneider; SILVA, Christian Luiz da; OLIVEIRA, Antonio Gonçalves de. Sistemas de custeio na gestão hospitalar. Curitiba: Ed. UTFPR, 2015.

${ }^{19}$ FERREIRA, Ximena Cardozo, op. cit.
} 
nistração Pública deixe de realizar as prestações positivas que garantam o mínimo existencial necessário à garantia da dignidade da pessoa humana ${ }^{20}$. Esse mínimo existencial é formado pelas condições básicas para a existência digna; costumeiramente fazem parte dele, entre outros, o direito a: educação fundamental, saúde básica, assistência social, acesso à justiça, saneamento básico e tutela do meio ambiente.

Diante desse núcleo central de direitos e de seu descumprimento pela Administração Pública, justifica-se a intervenção do Ministério Público e do Judiciário nas políticas públicas, seja para corrigir rumos seja para realizar sua implementação, independentemente da existência de lei ou de atuação da Administração Pública.

E é esse exatamente o caso da decisão em comento, em que a falta de prestação positiva eficaz por parte da Administração Pública leva a que sejam atingidos direitos fundamentais constantes do que se entende por mínimo existencial. A intervenção do Poder Judiciário não pode ser conceituada como uma invasão da atividade legislativa ou administrativa, pois não há reserva absoluta da lei para a formulação da política pública e a Constituição não reserva ao administrador margem de discricionariedade necessária à não intervenção ${ }^{21}$. Por isso, a intervenção judicial mostra-se compatível com a defesa de direitos fundamentais em uma sociedade democrática.

\section{Ministério Público e controle da Administração Pública}

O novo desenho institucional do Ministério Público, estabelecido a partir da Constituição de 1988, fez com que a instituição deixasse de atuar apenas como apêndice do Poder Executivo e se tornasse autônoma, sendo suas ações tidas como do próprio governo, uma vez que órgão independente. Nessa remodelagem, ficou a seu cargo a fiscalização do cumprimento das leis e dos próprios políticos, exercendo função de representante da sociedade ${ }^{22}$. No exercício dessas novas atribuições, o Ministério Público tem participação vital nos rumos da sociedade brasileira, assumindo inegável papel político, embora não partidário e vocacionado à interferência na condução dos negócios políticos estatais ${ }^{23}$.

Enquanto instituição de defesa da cidadania e órgão de controle da Administração Pública, seu papel no controle de políticas públicas é de grande relevância, uma vez que deve zelar pela implementação de políticas e serviços públicos

\footnotetext{
${ }^{20}$ GRINOVER, Ada Pellegrini. O controle jurisdicional de políticas públicas. In: GRINOVER, Ada Pelegrini; WATANABE, Kazuo. O controle jurisdicional de políticas públicas. Rio de Janeiro: Forense, 2013. p. 125-150.

${ }^{21} \mathrm{APPIO}$, Eduardo Fernando. O controle judicial das políticas públicas no Brasil. 2008. (Doutorado) - Programa de Pós-Graduação em Direito da Universidade Federal de Santa Catarina. Florianópolis, 2008.

${ }^{22}$ CARVALHO, Ernani; LEÃO, Natália. O novo desenho institucional do Ministério Público e o processo de judicialização da política. Revista de Direito GV, São Paulo, jul./dez. 2010.

${ }^{23}$ FERREIRA, Ximena Cardozo, op. cit.
} 
de qualidade ${ }^{24}$. Desse modo, torna-se o grande protagonista da defesa dos direitos sociais fundamentais e do controle social das políticas públicas. Ainda, sua fiscalização não está limitada ao exame da legalidade, mas abrange a análise da pertinência e adequação da política ou do programa governamental aos fins a que se propõe.

[...] Independente das indefinições restantes desse novo quadro institucional, o fato é que a politização de suas atribuições e o voluntarismo de seus integrantes transformaram o Ministério Público em um dos agentes principais do processo político no país. Seu combustível, embora reciclado, tem alto poder de explosão: a crença de que a sociedade civil é hipossuficiente, de que os poderes políticos estão degenerados, e alguém precisa fazer alguma coisa ${ }^{25}$.

Logo, é seu dever atuar quando a inércia da Administração ou quando o mau funcionamento do serviço público estiverem impedindo a concretização do próprio direito constitucional. Para tanto, cabe ao Ministério Público promover o inquérito civil e a ação civil pública para a defesa do patrimônio público e de outros interesses difusos e coletivos. No caso em comento, o Ministério Público utilizou de forma muito eficiente essas duas ferramentas jurídicas.

O inquérito civil é um instrumento extrajudicial em que são feitas recomendações, compromisso de ajustamento de conduta ou audiências públicas. É de se destacar que a realização de audiência pública no seio da comunidade em que o membro do Ministério Público desempenha suas atribuições é essencial para a eleição de prioridades e para uma atuação harmônica com os outros legitimados ativos para a questão ${ }^{26}$. $\mathrm{O}$ inquérito civil é capital, embora não obrigatório, à busca da verdade que deve nortear a atuação ministerial, identificando-se, por meio desse importante instrumento, os interesses porventura atingidos e as soluções mais adequadas ao caso concreto. Além disso, essa ferramenta pode ser utilizada para formação da convicção quanto à licitude/ilicitude da omissão administrativa na implementação de políticas públicas. Essa convicção é o que embasa a atuação e possibilita a conclusão do procedimento pela assinatura de compromisso de ajustamento de conduta, expedição de recomendação, ajuizamento de ação judicial ou arquivamento dos autos perante o Conselho Superior do Ministério Público ${ }^{27}$. Foi exatamente essa a ação tomada no caso em comento pelo Ministério Público, que durante vários anos buscou resolver a questão por meio da realização de audiências públicas, de inquérito civil e de assinatura de termo de ajuste de conduta.

\footnotetext{
${ }^{24}$ ISMAIL, Mona Lisa Duarte Abdo Aziz. O papel do Ministério Público no controle de políticas públicas. Boletim Científico ESMPU, Brasília, n. 42-43, p. 179-208, jan./dez. 2014.

${ }^{25}$ ARANTES, Rogério Bastos. op. cit., p. 98.

${ }^{26}$ FERRARESI, Eurico. A responsabilidade do Ministério Público no controle das políticas públicas. Cadernos de Direito, Piracicaba, v. 9, jan./dez. 2009.

${ }^{27}$ FERREIRA, Ximena Cardozo, op. cit.
} 
Caso essa ferramenta não surta efeito, o Ministério Público pode ajuizar ação civil pública sempre que constatar a inexistência ou inadequação de políticas públicas. Por isso, hodiernamente, a ação civil pública tem se tornado o instrumento destinado a permitir que as políticas públicas sejam levadas ao crivo do Poder Judiciário, de modo a se efetivarem os direitos fundamentais. É digno de nota que o Ministério Público ocupa papel de destaque nacional na defesa dos interesses supraindividuais, sendo responsável pelo ajuizamento de mais de $90 \%$ das ações civis públicas na defesa do meio ambiente. Porém, o uso eficaz dessa garantia ou seu enfraquecimento dependerá de como será utilizada pelos legitimados, tendo em vista o grande instrumento que é para que se exerça o poder de pressão da sociedade civil sobre os parlamentares, determinando o investimento estatal em meio ambiente $^{28}$. Ainda, também incumbe ao Ministério Público, ao tomar a decisão política sobre o ajuizamento da ação civil pública, recordar-se dos exatos contornos de sua atribuição, de modo a evitar demandas infrutíferas (natimortas) e desgaste institucional desnecessário ${ }^{29}$.

Todos esses cuidados foram tomadas no caso ora em comento, em que o Ministério Público, após mais de dez anos tentando por meios extrajudiciais conseguir que o ente estatal implementasse política pública adequada para o manejo de resíduos sólidos, optou pelo controle judicial. Destaque-se que foi somente com a decisão judicial que se cominou obrigação de fazer à Administração Pública.

O Poder Judiciário não mais se limita a examinar os aspectos extrínsecos da administração, pois pode analisar, ainda, as razões de conveniência e oportunidade, uma vez que essas razões devem observar critérios de moralidade e razoabilidade... Outorga de tutela específica para que a Administração destine do orçamento verba própria para cumpri-la ${ }^{30}$.

Desse modo, a ação civil pública é a principal ferramenta de atuação do Ministério Público na defesa de interesses difusos, coletivos e individuais homogêneos. Por meio dessa garantia constitucional se abre a possibilidade de cominação de obrigações de fazer e de não fazer à Administração Pública. A ação civil pública é basilar no controle da omissão administrativa na implementação de políticas públicas e na obtenção de decisão judicial para determinar ao ente estatal que atue de forma a dar concretude aos direitos sociais previstos na Constituição, em especial no que concerne aos direitos socioambientais ${ }^{31}$.

\footnotetext{
${ }^{28}$ CAPPELLI, Sílvia. Ação civil pública ambiental: a experiência brasileira, análise de jurisprudência. Cadernos do Programa de Pós-Graduação em Direito-PPGDir./UFRGS, v. 2, n. 5, 2004.

${ }^{29}$ FERREIRA, Ximena Cardozo, op. cit.

${ }^{30}$ Recurso Especial n. 1.367.549 - MG (2011/0132513-5).

${ }^{31}$ Id. Ibid.
} 


\section{Considerações finais}

A ideia de que o controle social de políticas públicas fere o princípio da separação dos Poderes já está majoritariamente ultrapassada. Do mesmo modo, está superada a ideia de que o administrador público sozinho tem a possibilidade de livremente escolher qual seu plano de governo e sobre a alocação de recursos públicos. Isso se deve, entre outros, ao fato de que as políticas públicas têm a finalidade de ser o meio pelo qual se afirmam ou se atingem os direitos fundamentais.

Assim, na inação da Administração Pública para afirmação do mínimo existencial constante dos direitos fundamentais, é dever do Ministério Público agir no sentido de garantir à sociedade o direito à boa Administração Pública e as prestações positivas que garantam a existência digna do ser humano. Isso se torna ainda mais importante quando se trata das questões ambientais, uma vez que a inação do poder público pode gerar não só consequências imediatas e danosas às presentes gerações, como pode inviabilizar a existência, com sadia qualidade de vida, das gerações futuras.

Nesse contexto, o controle social e o controle jurisdicional se tornam excelentes ferramentas para que os objetivos da tutela ambiental estabelecidos no artigo 225 da Constituição de 1988 sejam concretizados e para que esse direito fundamental possa ser garantido e exercido com o maior grau de eficácia possível.

\section{Referências}

ANDRADE, Pierre André da Rocha. Controle jurisdicional de políticas públicas: Estado Democrático de Direito e hermenêutica. 2008. Dissertação (Mestrado) - Programa de Pós-Graduação em Direito da Universidade Estácio de Sá. Rio de Janeiro: 2008.

APPIO, Eduardo Fernando. O controle judicial das políticas públicas no Brasil. 2008. (Doutorado) - Programa de Pós-Graduação em Direito da Universidade Federal de Santa Catarina. Florianópolis, 2008.

ARANTES, Rogério Bastos. Direito e política: o Ministério Público e a defesa dos direitos coletivos. Revista Brasileira de Ciências Sociais, v. 14, n. 39, p. 82-103, fev. 1999. Disponível em: <http://www.scielo.br/pdf/rbcsoc/v14n39/1723>.

BLANSKI, Beatriz Schneider; SILVA, Christian Luiz da; OLIVEIRA, Antonio Gonçalves de. Sistemas de custeio na gestão hospitalar. Curitiba: Ed. UTFPR, 2015.

CAPPELLI, Sílvia. Ação civil pública ambiental: a experiência brasileira, análise de jurisprudência. Cadernos do Programa de Pós-Graduação em Direito-PPGDir./UFRGS, v. 2, n. 5,2004 .

CARVALHO, Ernani; LEÃO, Natália. O novo desenho institucional do Ministério Público e o processo de judicialização da política. Revista de Direito GV, São Paulo, jul./dez. 2010. 
DORNELLAS, Eduardo Dias. Execução orçamentária como instrumento para a priorização de políticas públicas municipais secundárias: um estudo no município de Adrianópolis. 2015. Dissertação (Mestrado) - Programa de Pós-Graduação em Planejamento e Governança Pública, Universidade Tecnológica Federal do Paraná, 2015.

DYE, Thomas D. Understanding public policy. Englewood Cliffs, N.J.: Prentice-Hall, 1984.

FERRARESI, Eurico. A responsabilidade do Ministério Público no controle das políticas públicas. Cadernos de Direito, Piracicaba, v. 9, jan./dez. 2009.

FERREIRA, Ximena Cardozo. A atuação do Ministério Público na implementação de políticas públicas da área ambiental. Revista de Direito Ambiental, São Paulo, 2012. Disponível em: <http://www.mprs.mp.br/ambiente/doutrina/id377.htm>. Acesso em: 05 out. 2016.

GELINSKI, Carmen Rosario Ortiz G.; SIEBEL, Erni José. Formulação de políticas públicas: questões metodológicas relevantes. Revista de Ciências Humanas, Florianópolis, EDUFSC, v. 42 , n. $1 / 2$, abr./out. 2008.

GRINOVER, Ada Pellegrini. O controle jurisdicional de políticas públicas. In: GRINOVER, Ada Pelegrini; WATANABE, Kazuo. O controle jurisdicional de políticas públicas. Rio de Janeiro: Forense, 2013. p. 125-150.

IKUTA, Flávia Akemi. Resíduos sólidos urbanos no Pontal do Paranapanema/SP: inovação e desafios na coleta seletiva e organização de catadores. 2010. Tese (Doutorado) - Programa de Pós-Graduação em Geografia da Universidade Estadual Paulista. Presidente Prudente, 2010.

ISMAIL, Mona Lisa Duarte Abdo Aziz. O papel do Ministério Público no controle de políticas públicas. Boletim Científico ESMPU, Brasília, n. 42-43, p. 179-208, jan./dez. 2014.

MACHADO, Lucélia Simioni. Ponderação de bens e otimização do direito ao meio ambiente ecologicamente equilibrado na colisão de direitos fundamentais: uma abordagem a partir da teoria dos direitos fundamentais de Alexy. 2014. Dissertação (Mestrado) - Programa de PósGraduação em Direito da Universidade de Caxias do Sul, 2014.

MELlO, Maria Elisa Santos de Andrade. Controle judicial das políticas públicas. 2013. Monografia (Especialização) - Escola da Magistratura do Rio de Janeiro. Rio de Janeiro, 2013.

SILVA, Priscilla Lima de Carvalho. A judicialização da política e o controle judicial de políticas públicas: uma abordagem do tema na perspectiva da racionalidade das decisões judiciais. In: SEMINÁRIO INTERNACIONAL DE DEMANDAS SOCIAIS E POLÍTICAS PÚBLICAS NA SOCIEDADE CONTEMPORÂNEA, 11., 2014.

SOUZA, Celina. Políticas públicas: uma revisão da literatura. Sociologias, Porto Alegre, ano 8, n. 16, p. 20-45, jul./dez. 2006. Disponível em: <http://www.scielo.br/pdf/soc/n16/a03n16. pdf>. http://dx.doi.org/10.1590/S1517-45222006000200003. 
Controle jurisdicional de políticas públicas e o direito ao meio ambiente equilibrado

Ana Paula Myszczuk - Pós-Doutoranda no Programa de Pós-Graduação em Bioética da Pontifícia Universidade Católica do Paraná; doutora em Direito Econômico e Socioambiental pela Pontifícia Universidade Católica do Paraná, com estágio doutoral na Universidade do Deusto e Universidade do País Basco, desenvolvendo estudos na Cátedra Interuniversitaria de Derecho y Genoma Humano; mestre em Direito Econômico e Social pela Pontifícia Universidade Católica do Paraná; graduada em licenciatura em História e bacharelado em Direito pela Universidade Estadual de Ponta Grossa. Professora na Universidade Tecnológica Federal do Paraná e da Universidade Aberta do Brasil. Curitiba/PR, Brasil. E-mail: anap@ utfpr.edu.br.

Jussara Maria Leal de Meirelles - Pós-Doutora pelo Centro de Direito Biomédico da Universidade de Coimbra; doutora e mestre em Direito das Relações Sociais pela Universidade Federal do Paraná. Professora Titular de Direito Civil da Pontifícia Universidade Católica do Paraná, professora do Programa de Pós-Graduação em Direito Econômico e Socioambiental e do Programa de Pós-Graduação em Bioética da Pontifícia Universidade Católica do Paraná. Curitiba/PR, Brasil. 